\section{The dynamic relationship between economic policy uncertainty and substantial economic growth in China}

Economic policy uncertainty

\author{
Junchao Li and Shan Huang \\ School of Economics, Ocean University of China, Qingdao, China
}

\begin{abstract}
Purpose - Under the background of the overall increase of China's economic policy uncertainty and the urgent need for the transformation and upgrading of the substantial economy, this paper studies the time-varying causality between China's economic policy uncertainty and the growth of the substantial economy through bootstrap rolling window causality test, further refines economic policies and studies the causal differences between different types of economic policies and substantial economic growth, refining the conclusions of previous studies.

Design/methodology/approach - This paper first studies the causal relationship between China's economic policy uncertainty and substantial economic growth in the full sample period through bootstrap Granger causality test. Then, the paper tests the short-term and long-term stability of the parameters of the VAR model, and it is found that the model parameters are unstable in both the short and long term, so the results of the Granger causality test of the full sample are not credible. Finally, we conduct a dynamic test of the causal relationship between China's economic policy uncertainty and substantial economic growth by means of rolling window, so as to comprehensively analyze the dynamic characteristics and sudden changes of the relationship between them.
\end{abstract}

Findings - The research shows that economic policy uncertainty in China has a significant inhibiting effect on the growth of substantial economy. Growth in the substantial economy will drive up economic policy uncertainty before 2016 and restrain it after that. In addition, this paper further subdivides economic policy uncertainty to explore the causal differences between different types of economic policy uncertainty and substantial economic growth. The test results show that the relationship between them has obvious policy heterogeneity. The fiscal policy uncertainty and the monetary policy uncertainty, as the main policy means in China, has a significant impact on the growth rate of substantial economy in multiple ranges, but the effect time is short. Although trade policy uncertainty has a significant impact on the growth rate of substantial economy only during the financial crisis, the effect lasts for a long time. The impact of exchange rate and capital account policy uncertainty on the growth rate of substantial economy is mainly reflected after 2020.

Originality/value - The values of this paper are as follows: First, the economic policy uncertainty is combined with the growth of substantial economy, which makes up the gap of previous studies. Second, the economic policy uncertainty is further subdivided. The paper explores the causal differences between different types of economic policy uncertainties and the growth of substantial economy, so as to make the research more detailed. Finally, different from the previous static analysis, this paper uses dynamic model to examine the relationship between China's economic policy uncertainty and the growth of substantial economy from a dynamic perspective, with richer research conclusions.

Keywords Economic policy uncertainty, Substantial economy, Bootstrap rolling window causality test, Heterogeneity analysis

Paper type Research paper

\section{JEL Classification - C15, E63, O11}

(C) Junchao Li and Shan Huang. Published in Marine Economics and Management. Published by Emerald Publishing Limited. This article is published under the Creative Commons Attribution (CC BY 4.0) licence. Anyone may reproduce, distribute, translate and create derivative works of this article (for both commercial and non-commercial purposes), subject to full attribution to the original publication and authors. The full terms of this licence may be seen at http://creativecommons.org/licences/by/4.0/ legalcode
Received 4 April 2021 Revised 13 April 2021 Accepted 17 April 2021 
MAEM

4,2

114

\section{Introduction}

The concept of substantial economy has emerged since the financial crisis in 2008 , which is interpreted as an economic form of providing substantial goods and services in the Financial Times Lexicon. Over the past four decades, China's substantial economy has grown steadily under the policy of reform and opening up. No matter the scale of the substantial economy or its proportion in the national economy, China is a well-deserved substantial economy country. However, with the rapid development of the substantial industry, there are also some problems such as structural overbalance, excess capacity and insufficient profitability of the substantial sector. In this context, it is undoubtedly of great theoretical value and practical significance to comprehensively analyze the factors influencing the development of China's substantial economy and provide targeted suggestions for realizing the steady growth of the substantial sector.

After the financial crisis, there are still large fluctuations in the economy of various countries in the short term. This short-term instability hinders the further development of the substantial economy to a certain extent, especially in the important period when China's substantial industry is in urgent need of transformation. The high quality of the substantial economy development needs a stable macroeconomic environment. We need to deeply study the factors of short-term economic instability and realize the steady growth of the substantial sector. It has become a top priority. Among many factors, the impact of economic policy uncertainty on the growth of substantial economy is particularly prominent. This is mainly reflected in the fact that governments are eager to promote economic recovery, while making policies frequently, they ignore that frequent and unstable policies may aggravate macroeconomic fluctuations, and the unstable development environment of the substantial sector may counteract or even contradict the expected effects of the original policies. The uncertainty of economic policies will also increase the risks of investment and consumption, leading to the postponement or cancellation of corresponding economic behaviors by riskaverse people in the market, which is not conducive to the economic recovery after the crisis. Therefore, after the financial crisis, various countries frequently issued policies, but the adjustment effects are still unsatisfactory. Based on DSGE model, Basu and Bundick (2017) found that when the interest rate in monetary policy changes above zero, it will increase the negative impact of uncertainty while subduing economic fluctuations. In November 2019, the Dallas Federal Reserve indicated that the increase of economic policy uncertainty level was the main reason for the decline of stock price in the previous two years, which inhibited the growth of the S\&P 500 index by about $12 \%$.

Many scholars have found that after the crisis, the introduction of economic policies becomes more difficult to predict (Jurado et al., 2010). In other words, the level of policy uncertainty continues to rise. For China, the government's behavior during the period of economic recovery is changing rapidly. And there is a high degree of uncertainty in fiscal expenditure, monetary policy and tax system, and various emergencies that exacerbate the government policy uncertainty level. What's more, with the further highlight of global economic integration and self-interest policies of various countries, the impact of China's economic policy uncertainty on the growth of substantial industries presents a complex timevarying feature, and it is no longer possible to conduct a unified analysis on each time interval as in the past. Therefore, this paper is committed to studying the dynamic relationship between the China's economic policy uncertainty and the growth of the substantial economy, so as to provide prior guidance and supplement for the introduction of relevant policies and remedial measures, and also provide corresponding empirical materials and theoretical basis for the transformation and upgrading of China's substantial industry and high-quality economic development.

The structure of this paper is as follows. Section 2 reviews the current relevant research literature, and describes the transmission mechanisms between economic policy uncertainty 
and substantial economic growth. Section 3 describes the method and research data adopted in this paper, and carries out unit root test on the data. Section 4 makes an empirical analysis of the dynamic causal relationship between China's economic policy uncertainty and substantial economic growth. Section 5 summarizes the conclusions of this paper and puts forward corresponding suggestions.

\section{Literature review and transmission mechanisms}

\subsection{Literature review}

2.1.1 Research based on the substantial economy. The substantial economy is a kind of economic form different from the virtual economy. The original literature defines the substantial economy as economic activity related to the material production. The production process of the substantial economy refers to that the substantial manufacturers use the initial monetary capital to obtain the production factors used in production, through the consumption of these factors of production to production, the final product after trading into initial monetary form and realize the value of value-added (Cheng, 2003). Wu and Lin (2006) put forward that those industries related to the creation of material materials are included in the substantial economy, but other basic service industries are not included. According to the definition of material production, the primary industry, the secondary industry and the commercial and transportation industries in the tertiary industry as well as other material production activities should all belong to the category of substantial economy (Liu, 2011). Later, scholars' views on service industry changed. Zhou (2011) believes that in addition to the specific material economy, the service industry should also belong to the category of the substantial economy. Huang (2017) also pointed out that in the broadest sense, except for the financial industry and the increasingly virtualized real estate industry, all other industries belong to the substantial economy system.

At present, most of the literature on the substantial economy focuses on the interaction between the financial market and the substantial economy. On the one hand, the financial market is the product of the increase of residents' surplus wealth and the development of social credit system. It can effectively allocate social hot money to various uses, expand the financing channels of enterprises and facilitate the transformation and expansion of enterprises. In this regard, Rajan and Zingales (1998) argued that the improvement of financial level promotes the development of substantial economy, and they interact and promote each other. This is because it allocates the savings of residents to various investments, improves the efficiency of capital allocation (Ross and Levine, 1997), thus promoting the development of the substantial industry. On the other hand, compared with the substantial capital, the abnormal increase of the price of virtual assets will lead to the "siphon effect" of the virtual industry on social capital and crowd out industrial investment. The two deviates from the development, which will lead to the reduction of the output value of some substantial industries (Dore, 2008), and the lack of long-term growth power of the substantial economy. Claessens et al. (2009) also found that there is a negative feedback cyclical relationship between financial market and substantial economy fluctuations, and this correlation can be realized through credit channels (Jermann and Quadrini, 2012), and it has obvious heterogeneity characteristics for different types of enterprises (Martin and Ventura, 2012). Some scholars believe that the relationship between financial market and economic growth is more complex, showing a nonlinear characteristic (Eastern and Joseph, 2000; Ibrahim and Alaigidede, 2017). More specifically, the relationship between the two is generally inverted $U$-shaped (Lind and Mehlum, 2010; Cecchtti and Kharroubi, 2012), in other words, before reaching a certain level, the development of the financial system is beneficial to the substantial industry and can promote the growth of the substantial economy. Above this level, the former has an inhibitory effect on the latter.

\section{Economic policy uncertainty}


MAEM

4,2

2.1.2 Research based on measurement of economic policy uncertainty. Since the economic uncertainty will lead to the deviation between the market subject's expectation and the actual economic situation, the more uncertain factors in the economy, the greater the deviation between them. Therefore, some scholars will select some economic variables, explore the market participants' expectations of the economic variables, compare them with the actual situation, and then measure the economic uncertainty (Bachmann et al., 2013; Scotti, 2016). Bomberger (1996) made a statistical analysis on the subjective feelings and forecasts of market participants, and characterized the degree of economic uncertainty by its dispersion degree. Bloom (2009) measured the economic uncertainty based on the profit SD of sample enterprises.

For economic policy uncertainty, economic policy uncertainty index is generally selected as the proxy index of this factor, which shows the instability of government policy (Efthyvoulou and Vahter, 2015). The index is to retrieve the relevant sensitive words of newspapers, magazines or websites in a certain region, get the number of articles containing sensitive words in each period, and then deal with them through special methods. The uncertainty index of economic policy in the region is obtained. The uncertainty index of economic policy obtained by this method is relatively objective and can accurately measure the uncertainty degree of policy release in the whole economic system, but the disadvantage is that it is difficult to obtain data and the workload is huge.

Currently, the economic policy uncertainty index proposed by Baker et al. (2016) is widely used. However, the problem is that in the process of compiling China Index, the South China Morning Post of Hong Kong, China, is the only research sample, and the sample is not comprehensive and representative. In this regard, two scholars from Hong Kong Baptist University recalculate China's uncertainty index by similar methods based on ten newspapers in mainland China, and further construct the economic policy classification index according to the policy type, accurately depict the level of China's economic and policy uncertainty, and have been recognized by well-known international journals (Huang and Luk, 2020).

2.1.3 Research on the impact of economic policy uncertainty on economic growth. Economic policy uncertainty has a far-reaching impact on the development of the substantial economy. The positive impact of economic policy uncertainty on the substantial economy is that it contributes to the innovation behavior of enterprises (Stein and stone, 2013), especially exploratory innovation ( $\mathrm{Gu}$ et al., 2020), but there is significant enterprise heterogeneity in the relationship between them (Gu et al., 2018). Some scholars also put forward the opposite opinion, which is mainly reflected in the increase in economic policy uncertainty will increase the risk faced by lending banks, thus increasing the financing constraints of enterprises and inhibiting the innovation behaviors (Zhang and Feng, 2018; Hao et al., 2016), especially the breakthrough behavior with a relatively high degree of innovation (Zhang Feng et al., 2019). Many literatures also emphasize that policy uncertainty measures economic risk, and the increase of policy uncertainty means that the policy environment is more complex in this period. The uncertainty caused by policy causes people's pessimism towards the financial market, which leads to the financing difficulties of enterprises, and even hinders the occurrence of investment behavior (Rao et al., 2017; Chen and Wang, 2016).

For different types of policy uncertainty, Wang et al. (2019) believe that monetary policy uncertainty will inhibit the output level of the substantial economy, and the increase of default risk will aggravate this inhibitory effect. Although trade policy uncertainty can restrain the export of enterprises to a certain extent, it can improve the level of government subsidies, reduce the financing pressure of enterprises, promote the improvement of R\&D capacity, and then improve their competitiveness (Li and Liu, 2019). The decrease of trade policy uncertainty is helpful to increase the export scale and quality of enterprises 
(Mao, 2020). In addition, economic policy uncertainty can drive the flow of international capital with significant time-variability and difference (Wang and Lu, 2019). It also has a considerable risk shock effect on the international financial market, especially the uncertainty of US policy (Yang et al., 2020). When making policies, policymakers should consider not only the risk of one market, but also the risk transmission between different markets (Wang and Wang, 2018).

Based on the existing research results, the research on the economic policy uncertainty is mainly focused on the macro-economic level, and the research on the impact of substantial economic growth is less. Besides, most of the existing literature regards the economic policy uncertainty as a whole, and few analyze the heterogeneity of different types of economic policy uncertainty by decomposing economic policy uncertainty. Finally, there is almost no literature on the analysis of the dynamic impact of economic policy uncertainty. The dynamic influence that may exist can be further analyzed by combining the time-varying characteristics of economic policy uncertainty under different situations.

\subsection{The transmission mechanisms between economic policy uncertainty and substantial economic growth}

2.2.1 Growth option effect. Growth option effect refers to the process in which economic policy uncertainty encourages enterprises to invest at the present stage and increase R\&D investment by improving future potential returns, so as to promote enterprises' innovation in products, technology and management mode and realize economic recovery and prosperity. This effect is suitable for enterprises with market risk preference. These enterprises are committed to investing in some new projects with large risk coefficient and high uncertainty. What they pursue is that the benefits brought by success are greater than the costs brought by failure. Such projects are characterized by high technology content, high innovation and high cost. Through this effect, economic policy uncertainty improves the scale of future returns, encourages enterprises to invest and innovate, and also provides more possibilities for future economic development. However, only those "good volatility" can play the growth option effect, which is optimistic about the future prospects and believes that consumption, output and investment will rise in the future (Segal et al., 2015). It should also be noted that the uncertainty here refers to the economic policy uncertainty rather than the transaction uncertainty, which is harmful to the development of enterprises but not beneficial. Reducing the transaction uncertainty can not only stimulate the market participation of enterprises, improve the investment power of enterprises but also help to play the growth option effect of economic policy uncertainty on enterprises (Han et al., 2017), to promote economic prosperity and development.

2.2.2 Substantial option effect. The substantial option effect is the process of delaying investment due to the increase of economic policy uncertainty, which leads to investment fluctuations and affects the economic cycle. This is because this effect regards investment as a series of special options. When making investment decisions, investors will decide whether to invest immediately or not according to the profits of immediate exercise and deferred exercise of options. When economic policy uncertainty increases, the profits of deferred exercise of options are higher, enterprises are more willing to maintain the status quo, and the investment is delayed, but this kind of investment only refers to short-term investment, not long-term investment (Bloom, 2001). A basic assumption of its establishment is that investment opportunities are monopolized by the enterprise, and investment will only be delayed but not disappear (Doshi et al., 2017). Stokey and Nancy (2016) accurately describe the "wait-and-see" process of enterprise investment in the face of tax policy uncertainty by describing the two kinds of tax policy uncertainty processes. $\mathrm{Han}$ and $\mathrm{Hu}$ (2016) concluded that economic policy uncertainty is not conducive to the

\section{Economic policy uncertainty}


MAEM

4,2

118

improvement of social investment level, but the improvement of entrepreneur confidence may alleviate this adverse effect through the systematic GMM method. In addition, the increase of economic policy uncertainty will also inhibit the growth of bank lending (Zhang et al., 2015), aggravate the credit pressure of enterprises, and inhibit the investment behavior of enterprises.

2.2.3 Financial friction effect. Financial friction effect, that is, the increase of economic policy uncertainty leads to the increase of enterprise financing cost, aggravates the credit pressure of enterprises, and thus has a negative impact on enterprise investment, which will lead to the procyclical fluctuation of enterprise investment. During the economic recession, economic policy uncertainty development is high. In order to reduce the risks they bear, loan institutions often increase the loan interest rate and default cost of enterprises, thus aggravating the credit burden of enterprises. Some enterprises even go bankrupt due to the large borrowing pressure, and the investment level of the whole society is low. On the contrary, in the period of economic prosperity, the prospect of economic development is good, the unstable factors in the economy are less, the borrowing cost of enterprises is low, and the development momentum is good, thus promoting the investment level of the whole society. Caldara et al. (2016) believe that the economic policy uncertainty will have a certain impact on economic activities, and this impact is often achieved through credit channels. Li and Sun (2018) point out that financial friction will exacerbate the negative impact of economic policy uncertainty on investment growth. When economic policy uncertainty impacts the substantial economy, the intervention of financial variables becomes stronger and stronger (Yu and Song, 2020).

To sum up, it is not clear what the comprehensive impact of economic policy uncertainty on substantial economic growth is, how the latter affects the former, and whether there is a dynamic causal relationship between them. Therefore, the relationship between economic policy uncertainty and substantial economic growth needs empirical research.

\section{Methodology and data}

\subsection{Bootstrap rolling window causality test}

3.1.1 Full-sample granger causality test. This paper explores the causality between China's economic policy uncertainty and substantial economic growth through the Granger causality test of two variable VAR model. The common test statistics in Granger causality test include Wald statistics, likelihood ratio (LR) statistics and Lagrange multiplier (LM) statistics. However, these statistics only obey the standard asymptotic distribution under the condition of stable data. When the data is unstable, the above statistics cannot accurately estimate the VAR model and obtain the correct Granger test results. Shukur and Mantalos (2000, 2004) reconstruct LR statistics based on the bootstrap method, which improves the accuracy of Granger causality test and is suitable for causality analysis between non-stationary sequences (Wang and Li, 2019). Moreover, they relax the restriction of sample size and can accurately deal with the situation of less data. Therefore, this paper tests Granger causality between economic policy uncertainty and substantial economic growth through the Modified LR statistics.

In order to construct a modified LR statistic based on bootstrap method, a bivariate VAR $(P)$ model is set:

$$
y_{t}=\phi_{0}+\phi_{1} y_{t-1}+\cdots+\phi_{p} y_{t-p}+\varepsilon_{t}, t=1,2, \cdots, T
$$

For the convenience of observation, $y_{t}$ is written as $y_{t}=\left(y_{1 t}, y_{2 t}\right)^{\prime}, y_{1 t}$ and $y_{2 t}$ respectively indicate economic policy uncertainty and the growth of substantial economy, and (1) is expressed as: 


$$
\left[\begin{array}{l}
y_{1 t} \\
y_{2 t}
\end{array}\right]=\left[\begin{array}{l}
\phi_{10} \\
\phi_{20}
\end{array}\right]+\left[\begin{array}{ll}
\phi_{11}(L) & \phi_{12}(L) \\
\phi_{21}(L) & \phi_{22}(L)
\end{array}\right]\left[\begin{array}{l}
y_{1 t} \\
y_{2 t}
\end{array}\right]+\left[\begin{array}{l}
\varepsilon_{1 t} \\
\varepsilon_{2 t}
\end{array}\right]
$$

Economic policy uncertainty

where $p$ is the lag order of the variable, which is selected by Schwartz criterion. $\varepsilon_{t}=\left(\varepsilon_{1 t}, \varepsilon_{2 t}\right)^{\prime}$ is a white noise process with zero mean and zero covariance matrix. $\phi_{i j}=\sum_{m=1}^{p} \phi_{i j, m} L^{m}$, $i, j=1,2, L$ denotes the lag operator, which is calculated as $L^{k} x_{t}=x_{t-k}$. We set the null hypothesis of (2) as $\phi_{12, m}=0(m=1,2, \cdots, p)$ that the substantial economic growth is not the Granger cause of economic policy uncertainty. On the contrary, substantial economic growth is the Granger cause of economic policy uncertainty. Similarly, $\phi_{21, m}=0(m=1,2, \cdots, p)$ as another null hypothesis, we can test that economic policy uncertainty is not the Granger cause of substantial economic growth. If the null hypothesis is rejected, it proves that economic policy uncertainty is the Granger cause of substantial economic growth. In order to get the correct Granger test results, this paper uses the modified LR statistics to test.

3.1.2 Parameter stability test. Under the traditional Granger test framework, it is generally considered that the parameters in the VAR model are stable, but the complexity and variability of the economic environment determine that the parameters of the model have mutation, and structural changes may occur. The form of causality is not immutable, and the test results will change with the change of data interval and lag order. When the model parameters have structural mutation, the test results of the model may appear error or failure. Therefore, in order to accurately verify the real dynamic relationship between economic policy uncertainty and substantial economic growth, this paper tests the stability of the model parameters.

The parameter stability test is divided into short-term and long-term stability tests. On the one hand, this paper tests the stability of model parameters by constructing SUP- $F$, MEAN- $F$ and EXP-F test statistics, and obtains the critical value and $p$-value of corresponding statistics by bootstrap method, in which the above statistics are constructed based on the samples obtained by deleting the first $15 \%$ and the last $15 \%$ of the original data. To be specific, SUP- $F$ is to test if there exist shift in equations of VAR. MEAN-F and EXP-F is to test if the VAR model evolve gradually at different significant. On the other hand, this paper verifies the long-term stability of the parameters by $L_{c}$, so as to get more comprehensive longterm and short-term test results.

3.1.3 Sub-sample bootstrap rolling window causality test. Rolling window is a good timevarying processing method. By setting a fixed length of time interval, rolling from the beginning of the sample to the end of the sample, a series of sample intervals with the same length can be obtained for processing, which fully reflects the time-varying and mutability of the sample data. Suppose the length of the sample interval is $T$, the number of sub-samples is $\lambda$, so the end value of each window is $\tau=\lambda, \lambda+1, \ldots, T$, and the whole sample interval is divided into $T-1$ parts. In this paper, we test the causality of a series of sub-samples by bootstrap rolling window causality test, and judge the causality between variables through the modified LR statistics, so as to accurately get the time-varying characteristics of the causality between China's economic policy uncertainty and substantial economic growth. We also measure the impact of economic policy uncertainty on substantial economic growth and the impact of substantial economic growth on economic policy uncertainty respectively. By calculating the average value of all bootstrap estimators, two kinds of influence strength are obtained by $\Psi_{n}^{-1} \sum_{m-1}^{p} \widehat{\phi}_{21, m}^{*}$ and $\Psi_{n}^{-1} \sum_{k-1}^{p} \widehat{\phi}_{21, k}^{*}$, where $\Psi_{n}$ represents the number of bootstrap, and $\widehat{\phi}_{21, k}^{*}$ and $\widehat{\phi}_{21, k}^{*}$ are the value of bootstrap estimation. Test at $90 \%$ confidence 
MAEM

4,2

120

level, $\widehat{\phi}_{21, k}^{*}$ is the upper limit of the confidence interval, and $\widehat{\phi}_{21, k}^{*}$ is the lower limit of the confidence interval.

The advantage of the sub-samples rolling window causality test is that the rolling window method better reflects the time-varying causality between China's economic policy uncertainty and substantial economic growth, so that it can more accurately get the abrupt change points of causality in the sub-samples. However, the accuracy of the rolling window sub-samples test is limited by the length of the window period. If the window period is too long, the statistics calculated by sub-samples are not representative. If the window period is too short, although the test statistics are highly representative, the accuracy of the model test is reduced. To sum up, this paper takes 24 quarters as the length of rolling window.

\subsection{Data}

At present, the more extensive definition of the substantial economy is that it does not consider the substantial estate industry, nor the financial industry, but the rest of the national economy. However, there is no denying that industry accounts for a considerable proportion in the substantial economy. According to China's statistics, industrial added value accounts for about $37 \%$ of GDP excluding the added value of financial industry and real estate industry, far higher than that of other substantial industries (including transportation, construction, catering and accommodation, agriculture). In addition, considering the industry as the core part of China's substantial economy (Huang, 2017), it can effectively reflect the current development status of China's substantial economy, so this paper takes industry as a typical industry of the substantial economy, and takes the year-on-year growth rate of industrial added value as the proxy index of substantial economy growth for empirical analysis. First, this paper seasonally adjusts the quarterly data of industrial added value (IAV) and calculates the year-on-year growth rate (IAVG):

$$
\mathrm{IAVG}_{t, i}=\frac{\mathrm{IAV}_{t, i}-\mathrm{IAV}_{t-1, i}}{\mathrm{IAV}_{t-1, i}}
$$

where $\mathrm{IAV}_{t, i}$ represents the industrial added value in the $i$ quarter of the $t$ year, $\mathrm{IAVG}_{t, i}$ represents the year-on-year growth rate of the industrial added value in the $i$ quarter of the $t$ year.

As for the indicators to measure economic policy uncertainty, this paper selects economic policy uncertainty index published by Huang and Luk (2020), which is different from the previous calculation. Based on ten newspapers in mainland China, two scholars from Hong Kong Baptist University recalculate the uncertainty index of China's economic policy through keyword selection. Compared with economic policy uncertainty index in the previous literature, the compilation sample of this index is more comprehensive and representative, and its change characteristics over time are more consistent with the important economic policy events in China, which indicates that the quality of this index is more reliable, and this index is recognized by the international well-known journals (Huang and Luk, 2020). In addition, according to the different types of policies (fiscal policy, monetary policy, trade policy and exchange rate and capital account policy), the two scholars put forward a refined index of economic policy uncertainty to more comprehensively measure the changes of various economic policy uncertainties in China. Therefore, in order to accurately measure the uncertainty of Chinese government, this paper selects this kind of the economic policy uncertainty index. However, since the original index is monthly data, and the growth rate of industrial added value we calculated before is quarterly data, this paper calculates the 
average value of monthly data to obtain the quarterly data we need, and takes logarithm for it. The calculation process is as follows:

$$
\ln \left(\mathrm{EPU}_{j}\right)=\ln \left(\frac{\mathrm{EPU}_{j 1}+\mathrm{EPU}_{j 2}+\mathrm{EPU}_{j 3}}{3}\right)
$$

where $\mathrm{EPU}_{j 1}, \mathrm{EPU}_{j 2}$ and $\mathrm{EPU}_{j 3}$ respectively represent the economic policy uncertainty index of the first, second and third months in the $j$ quarter, and $\mathrm{EPU}_{j}$ represents the economic policy uncertainty index of the $j$ quarter.

The data interval of the above variables is from March 2000 to September 2020, and the data comes from CEInet Statistics database and the economic policy uncertainty index publishing website [1].

\subsection{Unit root test}

In this paper, $\mathrm{ADF}$ is used to test whether the variable has unit roots. The test results are shown in Table 1 . The table shows that the original sequence of all variables has unit roots at the significance level of 1 and $5 \%$. However, all the variable sequences are stationary at the confidence level of $1 \%$ after first-order difference, which indicates that these five variables are I (1) at the confidence level of $1 \%$.

\section{Empirical results}

\subsection{Full-sample bootstrap rolling window causality test}

According to Table 1, China's economic policy uncertainty (EPU) index and industrial added value growth rate (IAVG) are I(1). On this basis, this paper conducts a full sample Granger causality test, and conducts 10,000 repeated sampling based on bootstrap method to improve the rationality and accuracy of the test. According to Schwartz information criterion, the lag order is 2 . Table 2 reports the results of bootstrap rolling window causality test for the full sample between EPU and IAVG. It can be seen from Table 2 that at the significance level of $10 \%, p$-value cannot reject the null hypothesis. In other words, there is no two-way or one-way causal relationship between EPU and IAVG, which is contrary to our cognition. This is because when the sample data interval is relatively long, the model parameters may change. Therefore, the results of the full sample test may be wrong, and it is necessary to test the stability of the model parameters.

\subsection{Parameter stability test}

Tables 3 and 4 respectively report the parameter test results of EPU equation, IAVG equation and the VAR system. The null hypothesis corresponding to Sup- $F$ is that the parameters have

\begin{tabular}{lcc}
\hline Indicator & $\begin{array}{c}\text { T Statistics of original } \\
\text { sequence }\end{array}$ & $\begin{array}{c}\text { T Statistics of first order difference } \\
\text { sequence }\end{array}$ \\
\hline Industrial added value growth rate (IAVG) & -3.2393 & $-7.0747^{* * * *}$ \\
Economic policy uncertainty index $(\mathrm{EPU})$ & -2.5960 & $-13.5238^{* * * *}$ \\
Fiscal policy uncertainty $\left(\mathrm{EPU}_{f}\right)$ & -2.8646 & $-10.3231^{* * *}$ \\
Monetary policy uncertainty $\left(\mathrm{EPU}_{m}\right)$ & -2.6230 & $-12.7318^{* * *}$ \\
Trade policy uncertainty $\left(\mathrm{EPU}_{t}\right)$ & -0.1758 & $-8.9318^{* * * *}$ \\
Exchange rate and capital account policy & -2.4241 & $-14.0648^{* * * *}$ \\
uncertainty $\left(\mathrm{EPU}_{e}\right)$ & &
\end{tabular}

Note(s): ADF tests all contain constant term and slope term at the same time. *** and ** indicate 1 and $5 \%$ significance test, respectively

Economic policy uncertainty 
MAEM

4,2

\section{2}

Table 2.

Full-sample bootstrap rolling window causality test between EPU and IAVG no structural mutation, while the null hypothesis corresponding to Mean- $F$ and Exp- $F$ is that the parameters have no gradual changes along the time trajectory. The null hypothesis corresponding to $L_{c}$ is that the parameters of the model system are constant. It can be seen from Table 3 that at the significance level of $1 \%$, Sup- $F$, Mean- $F$ and Exp- $F$ all reject the null hypothesis of short-term parameter stability, which indicates that there are not only potential structural mutations in parameters in IAVG equation, EPU equation and the VAR system, but also gradual trend over time. The results of $L_{c}$ test of VAR model also shows that the overall parameters of VAR (2) system were unstable at the significance level of $1 \%$. As can be seen from Table 4, Sup- $F$, Mean- $F$, Exp- $F$ and $L_{c}$ test statistics all reject the null hypothesis of parameter stability in the long term at the significance level of $1 \%$.

According to the test results shows that in both the short and long term, the model parameters is not stable, all the sample test results are not reliable, unable to accurately depict the causal relationship between EPU and IAVG in different period. Therefore, the dynamic test of sub-samples is carried out by means of scrolling window in the following paper.

\subsection{Sub-sample bootstrap rolling window causality test}

Because the parameters are unstable, we study the dynamic causal relationship between China's EPU and IAVG from March 2000 to September 2020 by rolling window. The relevant test results are shown in Figure 1 and Figure 2. It should be noted that the window length of this paper is 24 quarters, so the test results are reduced by 24 quarters, but the test accuracy of the model is not affected.

\begin{tabular}{llcc}
\hline & The null hypothesis & The modified LR statistics & Bootstrap $p$-value \\
\hline EPU and IAVG & $\mathrm{H}_{0}$ : EPU does not Granger cause IAVG & 4.7065 & 0.1360 \\
& $\mathrm{H}_{0}$ : IAVG does not Granger cause EPU & 0.3309 & 0.8610
\end{tabular}

Note(s): *,** and *** respectively represent the rejection of the null hypothesis at the significance level of $10 \%, 5$ and $1 \%$, and we calculate $p$-values using 10000 bootstrap repetitions

\section{Table 3.}

Short-term parameter stability test of EPU and IAVG

\begin{tabular}{lcccccc}
\hline & \multicolumn{2}{c}{ IAVG equation } & \multicolumn{2}{c}{ EPU equation } & \multicolumn{2}{c}{ VAR(2) system } \\
& Statistics & Bootstrap $p$-value & Statistics & Bootstrap $p$-value & Statistics & Bootstrap $p$-value \\
\hline Sup- $F$ & $67.1930^{* * * *}$ & 0.0000 & $43.5023^{* * * *}$ & 0.0000 & $57.4181^{* * * *}$ & 0.0000 \\
Mean $-F$ & $17.4283^{* * *}$ & 0.0001 & $20.6754^{* * *}$ & 0.0000 & $29.4393^{* * *}$ & 0.0000 \\
Exp- $F$ & $29.5460^{* * *}$ & 0.0000 & $17.8332^{* * *}$ & 0.0000 & $24.9442^{* * * *}$ & 0.0000 \\
$L_{C}$ & - & - & - & - & $5.7258^{* * *}$ & 0.0050
\end{tabular}

Note(s): *, ** and $* * *$ respectively represent the rejection of the null hypothesis at the significance level of $10 \%, 5$ and $1 \%$, and we calculate $p$-values using 10000 bootstrap repetitions
Table 4.

Long-term parameter stability test of EPU and IAVG

\begin{tabular}{lcccl}
\hline & Sup $F$ & Mean- $F$ & Exp- $F$ & $L_{C}$ test \\
\hline IAVG $=\alpha+\beta^{*} \mathrm{EPU}$ & $58.4459^{* * *}$ & $19.1190^{* * * *}$ & $25.8262^{* * * *}$ & $3.1740^{* * * *}$ \\
Bootstrap $p$-value & 0.0000 & 0.0000 & 0.0000 & 0.0050
\end{tabular}

Note(s): *** and *** respectively represent the rejection of the null hypothesis at the significance level of 10,5 and $1 \%$, and we calculate $p$-values using 10000 bootstrap repetitions 

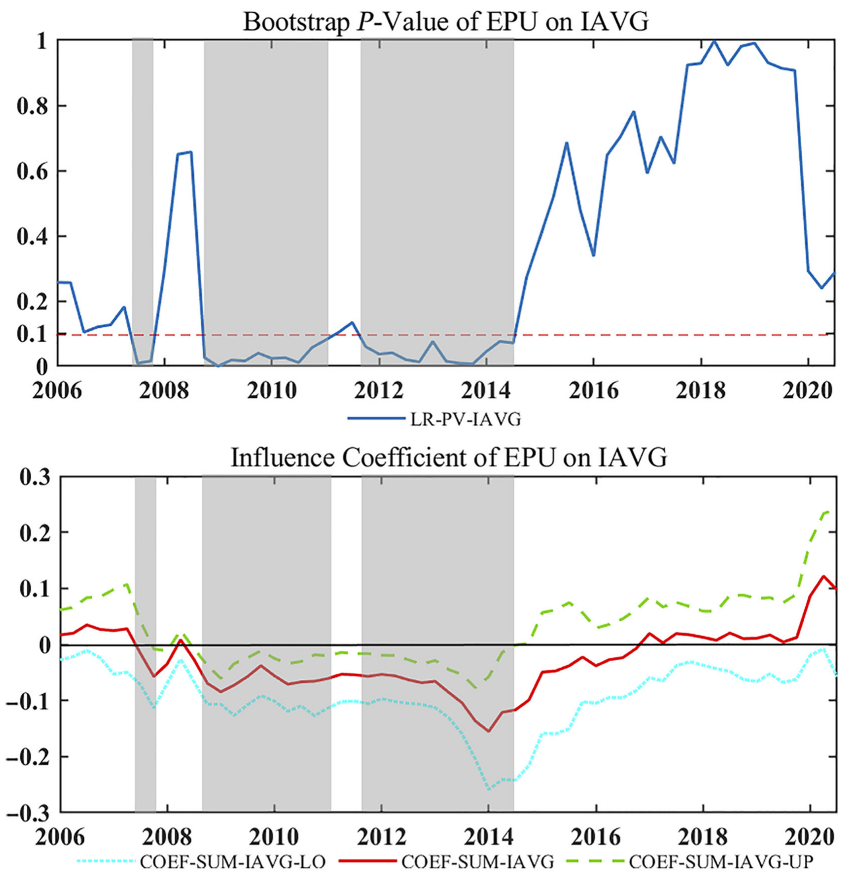

Note(s): Shadow area is time interval where $p$-value is less than 0.1 , and there are bootstrap $p$-value and influence coefficient (including mean value, maximum value and minimum value) of EPU on IAVG
Economic policy uncertainty

123
Figure.1. Sub-sample bootstrap rolling window causality test of EPU on IAVG

Figure 1 shows that EPU does Granger cause IAVG. Coefficient less than 0 indicates that EPU has a negative impact on IAVG, while coefficient greater than 0 means that the former has promoting effect on the latter. According to Figure 1, from September 2007 to December 2007, and from December 2008 to March 2011, EPU has a significant negative impact on IAVG. During this period, affected by the world financial crisis, the Chinese government frequently implemented policies, but the depression of economic situation and the instability of economic policies seriously damped the confidence of market players, which was not conducive to the exertion of growth option effect. On the other hand, the increase of economic policy uncertainty also stimulates the cautious motivation of financial institutions. The sharp decline of social credit scale is not unfavorable to the investment behavior of individuals and the financing behavior of substantial enterprises, resulting in huge financial friction effect and substantial option effect. The vitality of substantial economy market is reduced, and the growth rate of industrial added value is also sharply reduced.

From December 2011 to September 2014, EPU continued to have a negative impact on IAVG, and this impact increases over time as a whole, and begins to decline after reaching the peak in 2014. This is the period of economic overheating caused by China's policy to recover the economy. The prosperous economic outlook greatly weakened the effect of substantial option, and the growth option effect of economic policy uncertainty was obvious, which continuously promoted the domestic fixed asset investment. By 2013, the total investment in fixed assets of the whole society has accounted for $83.4 \%$ of GDP, and it, meanwhile, has also 
MAEM

4,2

\section{4}

Figure 2.

Sub-sample bootstrap rolling window causality test of IAVG on EPU
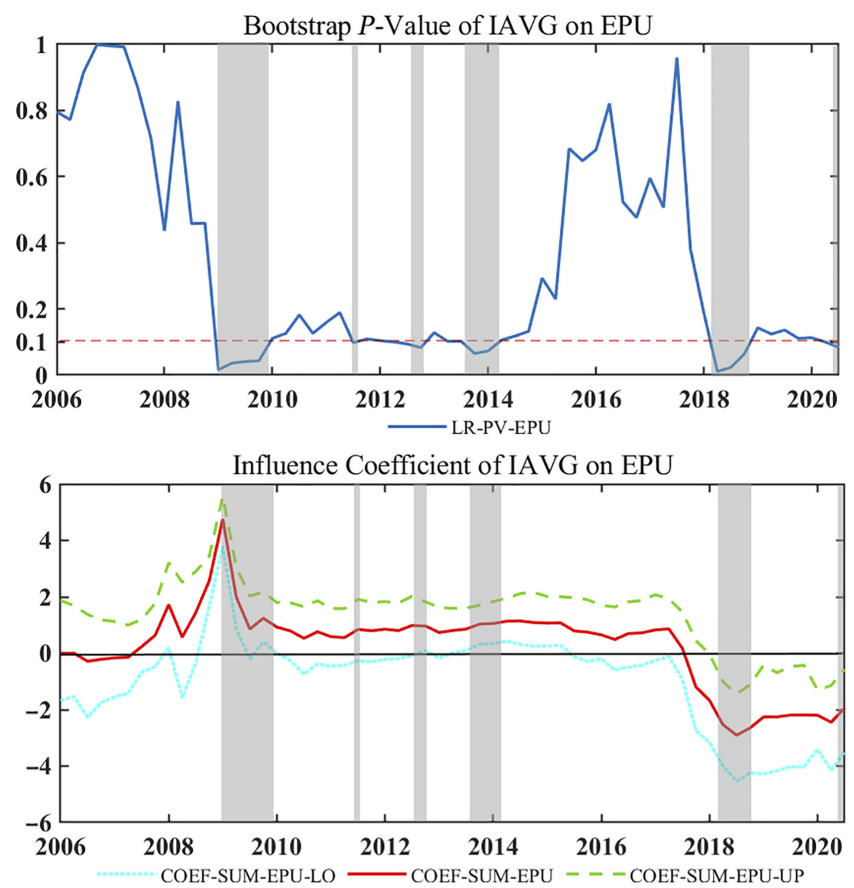

Note(s): Shadow area is time interval where $p$-value is less than 0.1 , and there are bootstrap $p$-value and influence coefficient (including mean value, maximum value and minimum value) of IAVG on EPU

pulled China's production capacity to an unprecedented level, including high-energy consumption and low-quality nonprofit enterprises production capacity, which was difficult to meet the increasingly diverse needs of market participants, has caused the embarrassing situation of "more production, greater loss." To sum up, the introduction of economic policies in different situations has different effects on the growth of substantial economy, but the former generally shows inhibiting effect on the latter. Therefore, when the government regulates the economy through policy means, it should assess the situation. Otherwise, it will only exacerbate the economic policies uncertainty, result in policy failure or even contradiction, and hinder the development of the substantial industry.

Similarly, Figure 2 shows the time interval where IAVG dose Granger cause EPU, and the direction and extent of the impact of IAVG on EPU. According to Figure 2, IAVG has a positive impact on EPU in several periods, including March 2009 to December 2009, September 2011, June 2012 to December 2012 and December 2013 to March 2014. In the above interval, IAVG has a greater impact on EPU than EPU on the IAVG, but its action time is shorter, which indicates that the government should also formulate policies according to the growth of the substantial economy at this stage. Although the effect of substantial economy growth on policy-making is greater, the action time is short. At this time, China's production capacity rapid improved. The occurrence of the financial crisis punctured the asset bubbles that were rising steadily on the eve of the crisis, but also released some of the economic downward pressure, resulting in a new round of growth cycle of virtual asset bubbles, and 
social capital flow to the virtual economy. As a result, the R\&D expenditure of enterprises was greatly reduced, and the technology development was into a dilemma. However, under the incentive of national fiscal expenditure and tax, the capacity of the substantial industry was growing, which inevitably led to inefficient low-end excess capacity, so the state has also introduced a series of policies and measures, but most of them were temporary measures, leading to the increase of EPU, and the problem of excess capacity has not been fundamentally solved.

It also can be seen from Figure 2 that IAVG has a negative effect on EPU in the two time interval after 2016. It was not until 2016 that overcapacity problem attracted the government's attention. China began to implement the policy to reduce excess capacity. The backward capacity was greatly reduced, promoting enterprise merger and reorganization. By 2018, reducing excess capacity of the substantial industry has achieved remarkable results, the production and operation of the substantial sector has grown steadily, and the development of the substantial economy has stabilized economy and the people's livelihood, and EPU has declined. In addition, influenced by COVID-19, China's substantial economy growth rate declined slightly at the beginning of 2020, which caused the economic policy uncertainty to rise to a certain extent. But with China's government's active efforts to promote resumption of labor and recovery, the market vitality was stimulated, and the substantial economy's role in promoting economic policy uncertainty was slowly weakening. It indicates that China's measures in dealing with COVID-19 were very effective.

\subsection{Heterogeneity analysis}

Considering that the degree of uncertainty of different types of economic policies is different, this part uses the policy uncertainty index proposed by Huang and Luk (2020) to divide the EPU into fiscal policy uncertainty $\left(\mathrm{EPU}_{f}\right)$, monetary policy uncertainty $\left(\mathrm{EPU}_{m}\right)$, trade policy uncertainty $\left(\mathrm{EPU}_{t}\right)$, exchange rate and capital account policy uncertainty $\left(\mathrm{EPU}_{e}\right)$, and makes a comparative analysis of difference of causality between four economic policy uncertainty index and the substantial economic growth.

4.4.1 Full-sample bootstrap rolling window causality test. According to Schwartz criterion, it is determined that the optimal lag order of each model is 2, and VAR (2) model is constructed. The bootstrap rolling window causality test for the full sample of various types of EPU and IAVG are shown in Table 5.

According to Table 5, in the whole sample range, there is no significant one-way or twoway casual relationship between $\mathrm{EPU}_{f}$ and IAVG, while $\mathrm{EPU}_{m}, \mathrm{EPU}_{t}, \mathrm{EPU}_{e}$ all have a significant impact on IAVG, but on the contrary, IAVG does not Granger cause policy uncertainty. Considering that the parameters of VAR model may have structural changes

\begin{tabular}{llcc}
\hline & The null hypothesis & The modified LR statistics & Bootstrap $p$-value \\
\hline EPU $_{f}$ and IAVG & $\mathrm{H} 0: \mathrm{EPU}_{f}$ does not Granger cause IAVG & 2.0654 & 0.3670 \\
& $\mathrm{H} 0: \mathrm{IAVG}$ does not Granger cause EPU & 0.8265 & 0.6630 \\
$\mathrm{EPU}_{m}$ and IAVG & $\mathrm{H} 0: \mathrm{EP}_{m}$ does not Granger cause IAVG & $5.4585^{*}$ & 0.0790 \\
& $\mathrm{H} 0: \mathrm{IAVG}$ does not Granger cause EPU & 1.6769 & 0.4440 \\
$\mathrm{EPU}_{t}$ and IAVG & $\mathrm{H} 0: \mathrm{EU}_{t}$ does not Granger cause IAVG & $5.0977^{* *}$ & 0.0390 \\
& $\mathrm{H} 0: \mathrm{IAVG}^{*}$ does not Granger cause EPU & 0.4075 & 0.5820 \\
$\mathrm{EPU}_{e}$ and IAVG & $\mathrm{H} 0: \mathrm{EPU}$ does not Granger cause IAVG & $5.3199 *$ & 0.0640 \\
& $\mathrm{H} 0: \mathrm{IAVG}$ does not Granger cause EPU & 1.7122 & 0.4440
\end{tabular}

Note(s): *** and $* * *$ respectively represent the rejection of the null hypothesis at the significance level of 10,5 and $1 \%$, and we calculate $p$-values using 10000 bootstrap repetitions

\section{Economic policy uncertainty} 作 
MAEM

4,2

\section{6}

and instability in the samples with long time interval, in order to improve the accuracy of the results, we need to test the stability of the model parameters.

4.4.2 Parameter stability test. Tables 6 and 7 are the test results of short-term and longterm parameter stability of various types of EPU and IAVG. According to the test results, whether in the short term or long term, the parameters of each VAR model are not stable. This means that the results derived from the full-sample causality tests would become invalid.

4.4.3 Sub-sample bootstrap rolling window causality test. Figures 3-6 respectively show the sub-sample test results of various EPU and IAVG. It can be seen from the figures that different types of EPU have different influences on IAVG. Among them, the impact of $\mathrm{EPU}_{t}$ on IAVG lasts longer than other policy uncertainties, but it has a significant impact on IAVG only from March 2009 to December 2009. Fiscal policy and monetary policy as the main means of government regulation, so $\mathrm{EPU}_{f}$ and $\mathrm{EPU}_{m}$ affect the growth rate of China's substantial industry in multiple intervals, but the duration is short. $\mathrm{EPU}_{e}$ has a weak impact on IAVG in the time interval before 2020, and $\mathrm{EPU}_{e}$ and $\mathrm{EPU}_{m}$ have a prominent impact on the growth of China's substantial economy at the beginning of 2020. As far as the impact is

Table 6.

Short-term parameter stability test of various types of EPU and IAVG

\begin{tabular}{|c|c|c|c|c|c|c|c|}
\hline & & $\begin{array}{l}\text { IAVG } \\
\text { Statistics }\end{array}$ & $\begin{array}{l}\text { uation } \\
\text { Bootstrap } \\
p \text {-value }\end{array}$ & $\begin{array}{l}\text { EPU e } \\
\text { Statistics }\end{array}$ & $\begin{array}{l}\text { lation } \\
\text { Bootstrap } \\
p \text {-value }\end{array}$ & $\begin{array}{r}\text { VAR } \\
\text { Statistics }\end{array}$ & $\begin{array}{l}\text { stem } \\
\text { Bootstrap } \\
p \text {-value }\end{array}$ \\
\hline \multirow[t]{4}{*}{$\mathrm{EPU}_{f}$} & Sup- $F$ & $42.8214^{* * *}$ & 0.0000 & $33.4348^{* * * *}$ & 0.0001 & $41.6271^{* * * *}$ & 0.0002 \\
\hline & Mean- $F$ & $12.7436 * * *$ & 0.0041 & $19.9816^{\text {**** }}$ & 0.0000 & $23.0885^{* * * *}$ & 0.0008 \\
\hline & Exp- $F$ & 17.5147 *** & 0.0000 & $14.5076^{* * * *}$ & 0.0000 & $17.1965^{* * * *}$ & 0.0002 \\
\hline & $L_{C}$ & - & - & - & - & $4.4874^{* * * *}$ & 0.0050 \\
\hline \multirow[t]{4}{*}{$\mathrm{EPU}_{m}$} & Sup- $F$ & $51.0540 * * *$ & 0.0000 & 51.6087 **** & 0.0000 & $44.1041^{* * * *}$ & 0.0001 \\
\hline & Mean- $F$ & $13.5334 * * *$ & 0.0023 & 12.6750 **** & 0.0043 & $18.8451^{* * * *}$ & 0.0089 \\
\hline & Exp-F & $22.3276^{\text {*** }}$ & 0.0000 & $21.7439 * * *$ & 0.0000 & $18.2720 * * *$ & 0.0000 \\
\hline & $L_{C}$ & - & - & - & - & $4.3675 * * *$ & 0.0050 \\
\hline \multirow[t]{4}{*}{$\mathrm{EPU}_{t}$} & Sup- $F$ & $75.9025^{* * *}$ & 0.0000 & 26.6683 **** & 0.0019 & $50.8361 * * *$ & 0.0000 \\
\hline & Mean- $F$ & 15.6610 *** & 0.0005 & 11.8946 *** & 0.0073 & $19.6756^{* * * *}$ & 0.0057 \\
\hline & Exp-F & $33.9251^{* * * *}$ & 0.0000 & $9.6480 * * *$ & 0.0020 & $22.2858 * * *$ & 0.0000 \\
\hline & $L_{C}$ & - & - & - & - & $5.0748 * * *$ & 0.0050 \\
\hline \multirow{4}{*}{$\mathrm{EPU}_{e}$} & Sup- $F$ & $82.8486^{* * *}$ & 0.0000 & $55.1467 * * *$ & 0.0000 & $53.2893 * * *$ & 0.0000 \\
\hline & Mean- $F$ & $20.6252^{* * * *}$ & 0.0000 & $10.3275^{* * *}$ & 0.0206 & $17.3207^{* * *}$ & 0.0199 \\
\hline & Exp-F & $37.6052 * * *$ & 0.0000 & $23.5154^{* * * *}$ & 0.0000 & $22.6162 * * *$ & 0.0000 \\
\hline & $L_{C}$ & - & - & - & - & $4.6565^{* * * *}$ & 0.0050 \\
\hline
\end{tabular}

Note(s): *** and *** respectively represent the rejection of the null hypothesis at the significance level of 10,5 and $1 \%$, and we calculate $p$-values using 10000 bootstrap repetitions

\begin{tabular}{llcccl}
\hline & & Sup $-F$ & Mean- $F$ & Exp- $F$ & $L_{C}$ \\
\hline $\mathrm{EPU}_{f}$ & IAVG $=\alpha+\beta^{*} \mathrm{EPU}_{f}$ & $59.8577^{* * * *}$ & $20.5292^{* * *}$ & $26.4589 * * *$ & $2.5352^{* * * *}$ \\
& Bootstrap $p$-value & 0.0000 & 0.0000 & 0.0000 & 0.0050 \\
$\mathrm{EPU}_{m}$ & IAVG $=\alpha+\beta^{*} \mathrm{EPU}$ & $77.7210^{* * * *}$ & $29.2336^{* * *}$ & 35.4217 & $3.1700^{* * * *}$ \\
& Bootstrap $p$-value & 0.0000 & 0.0002 & 0.2793 & 0.0050 \\
$\mathrm{EPU}_{t}$ & IAVG $=\alpha+\beta^{*} \mathrm{EPU}$ & $60.5756^{* * * *}$ & $19.5676^{* * *}$ & $26.9647^{* * *}$ & $2.1569 * * *$ \\
& Bootstrap $p$-value & 0.0000 & 0.0000 & 0.0001 & 0.0050 \\
$\mathrm{EPU}_{e}$ & IAVG $=\alpha+\beta^{*} \mathrm{EPU}$ & $82.0445^{* * * *}$ & $30.1271^{* * *}$ & 37.4008 & $3.3735^{* * *}$ \\
& Bootstrap $p$-value & 0.0000 & 0.0000 & 0.3331 & 0.0050
\end{tabular}

\section{Table 7.}

Long-term parameter stability test of various types of EPU and IAVG
Note(s): *** and *** respectively represent the rejection of the null hypothesis at the significance level of 10,5 and $1 \%$, and we calculate $p$-values using 10000 bootstrap repetitions 

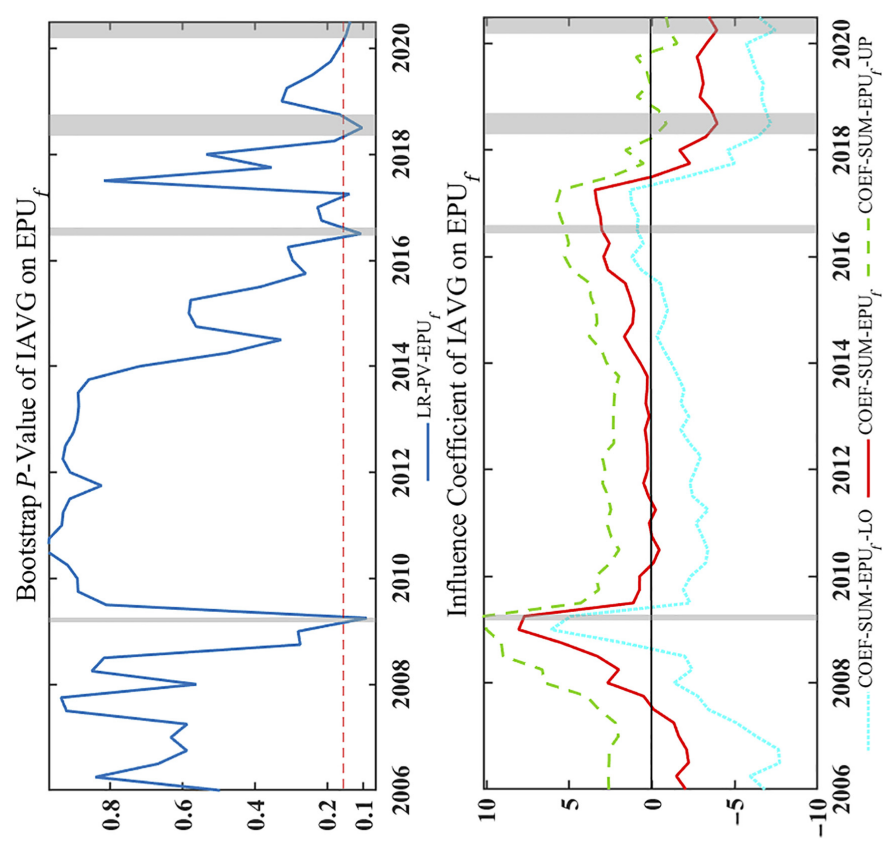

Economic

policy uncertainty

言 127

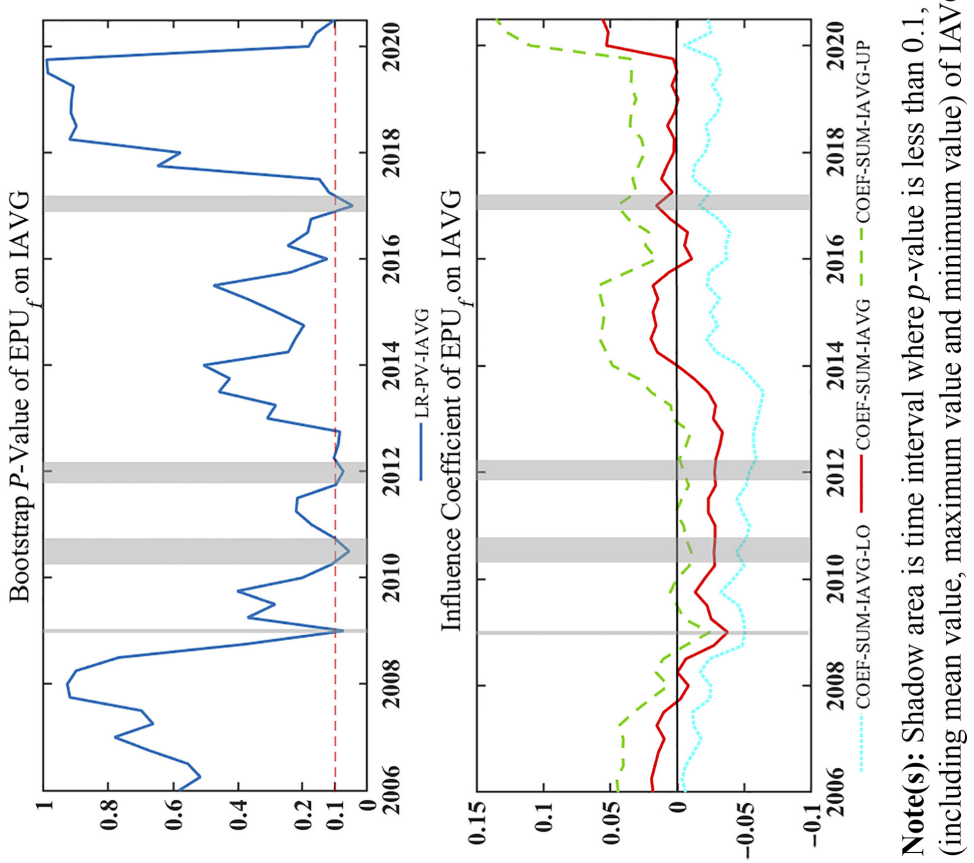

Figure 3. Sub-sample bootstrap rolling window causality test of $\mathrm{EPU}_{f}$ and IAVG 
MAEM

4,2

128

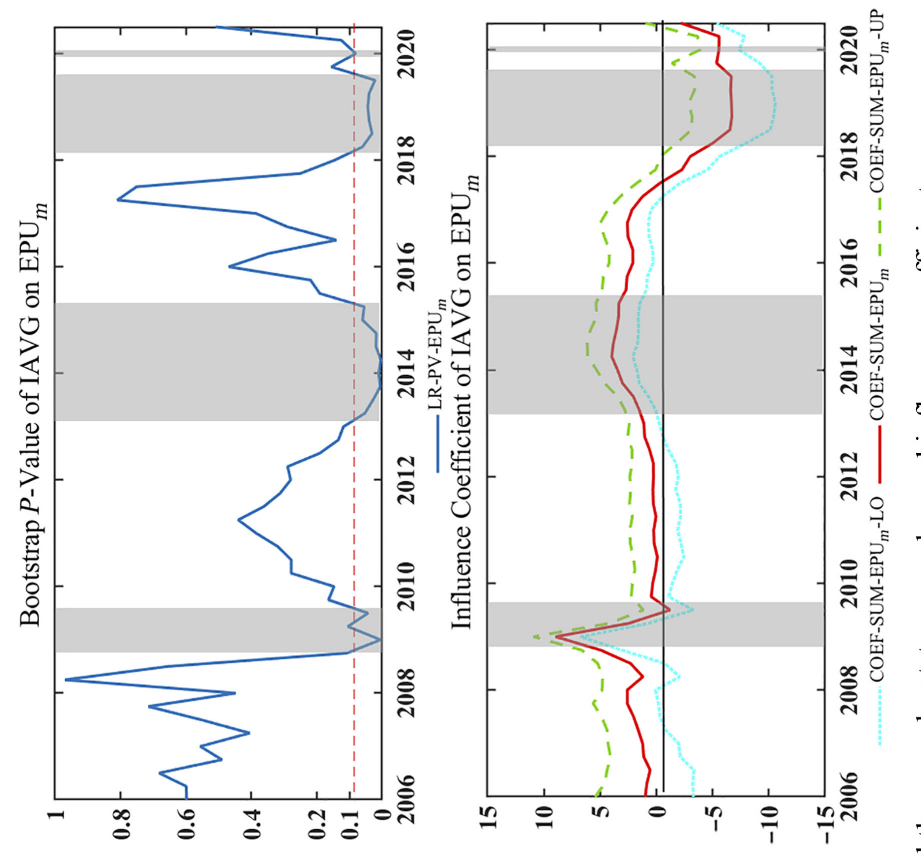

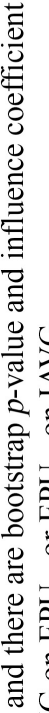

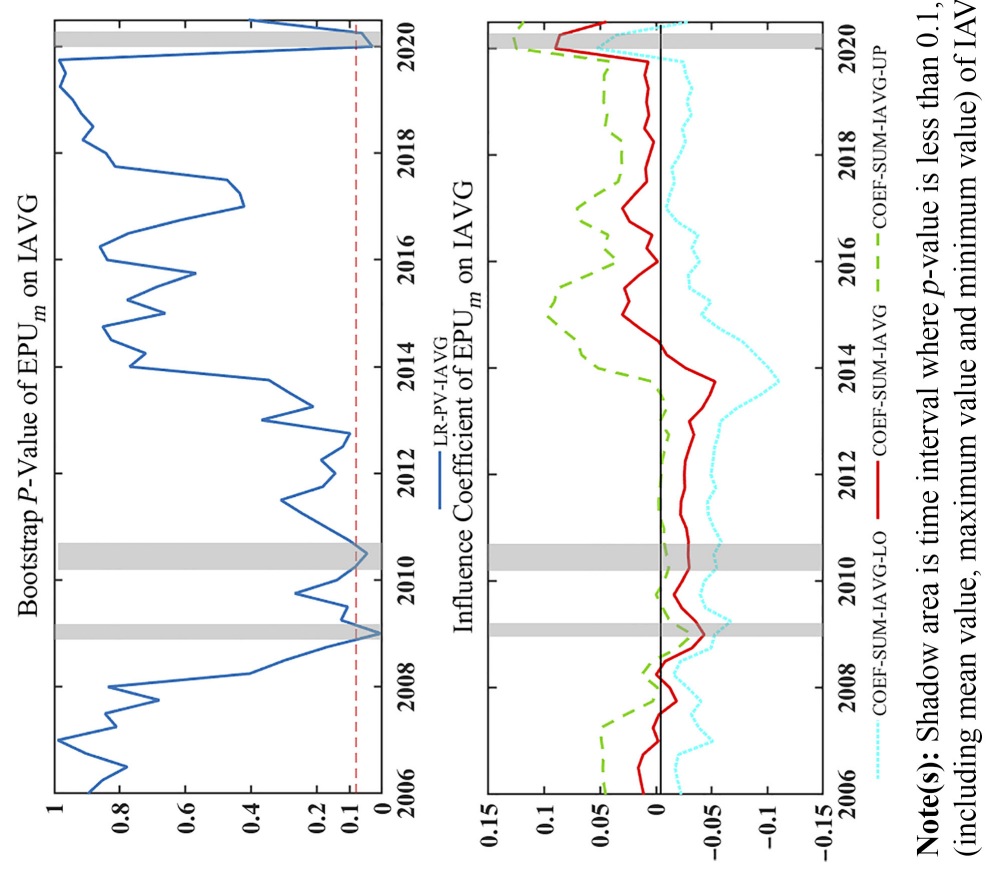

Figure 4 .

Sub-sample bootstrap rolling window causality test of $\mathrm{EPU}_{m}$ and IAVG 

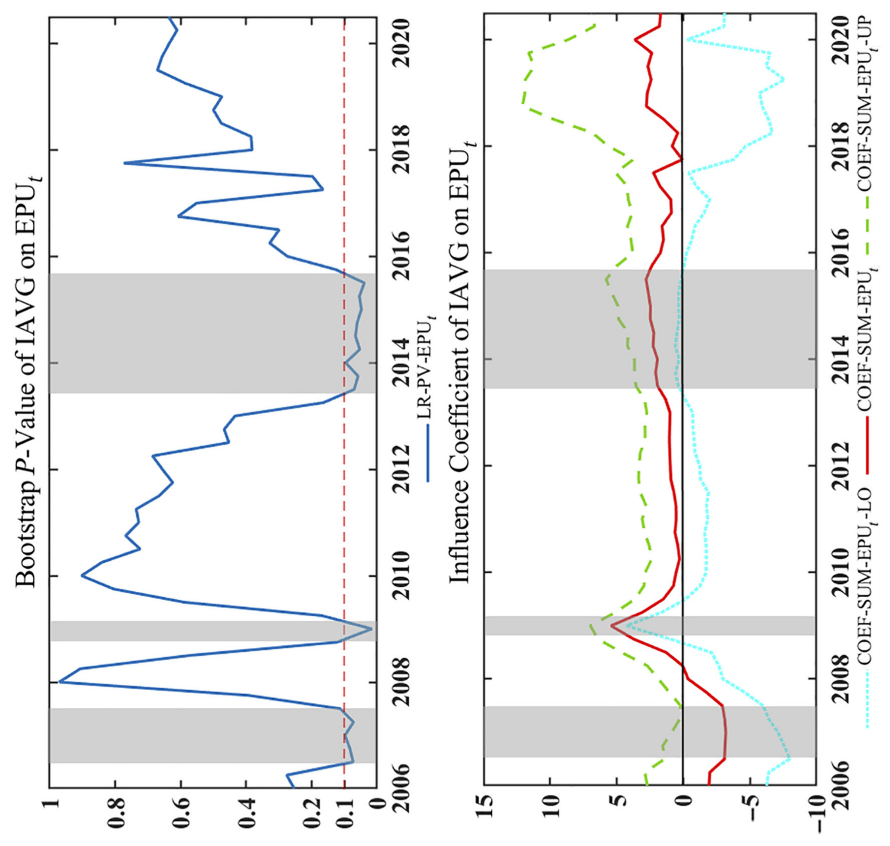

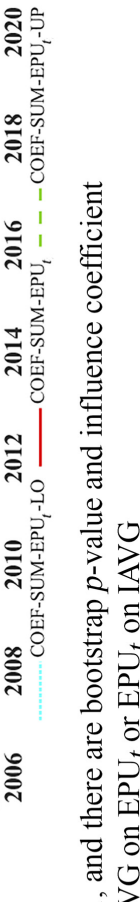

Economic

policy uncertainty

129

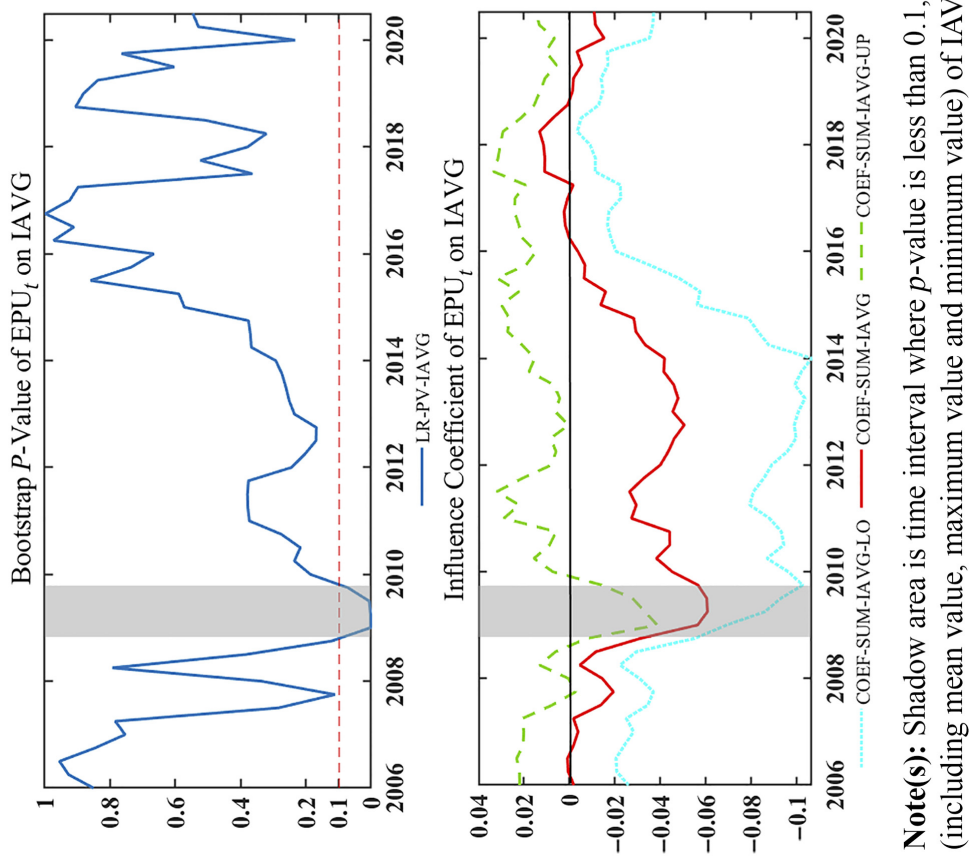

Figure 5.

Sub-sample bootstrap rolling window causality test of $\mathrm{EPU}_{t}$ and IAVG 
MAEM

4,2

130
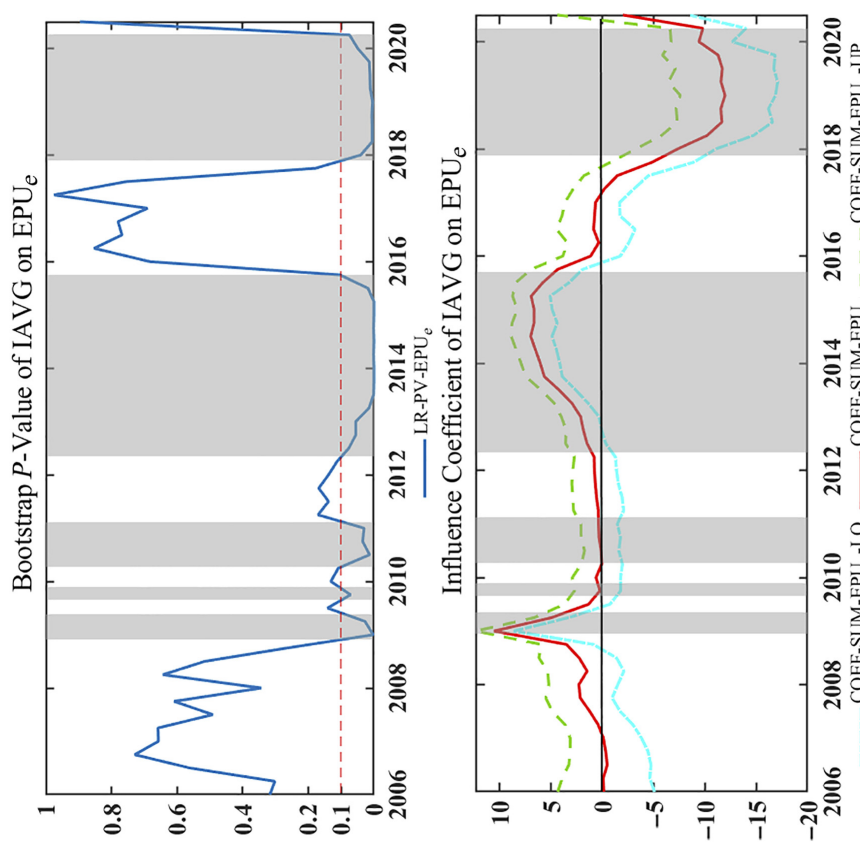

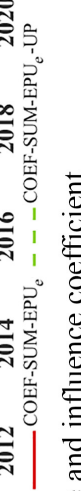

草

镉

है ซิ

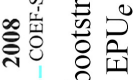

ญ ठ

ส

氖高

흐

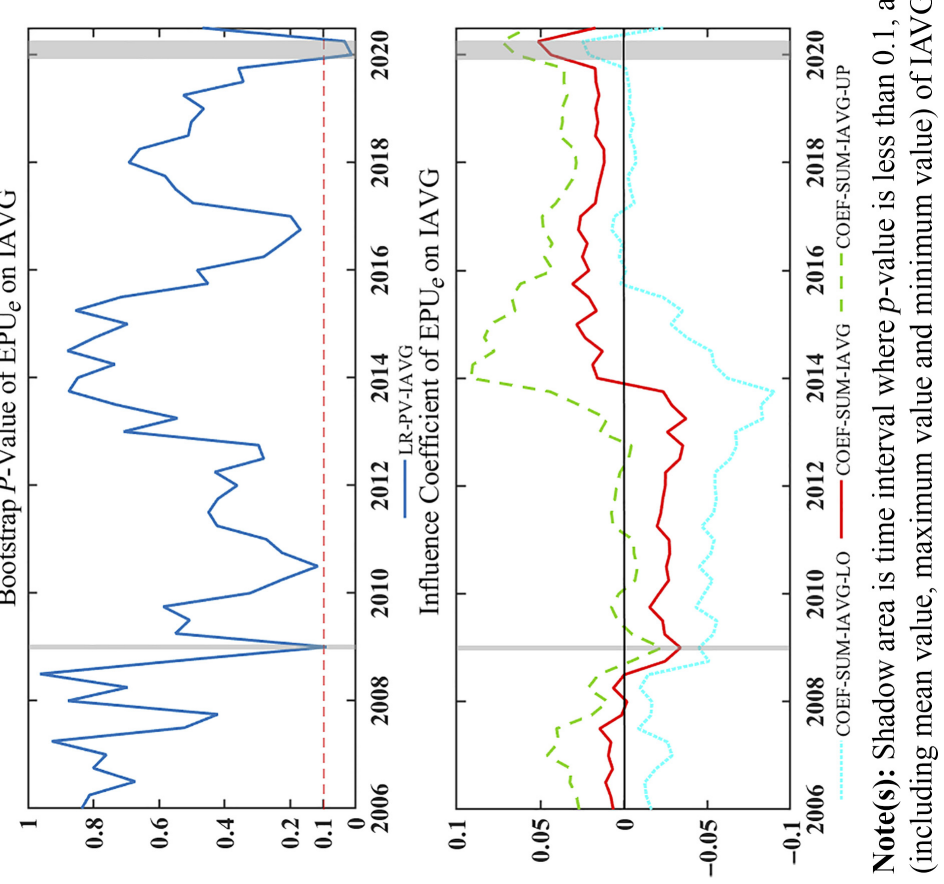

Figure 6.

Sub-sample bootstrap rolling window causality test of $\mathrm{EPU}_{e}$ and IAVG 
concerned, all policies have a significant negative impact on IAVG in the significant time interval before 2016. A series of economic policies issued by the government in response to the economic weakness have pushed up the degree of economic uncertainty. The unstable policy environment and a large amount of low-end capacity hoarding have caused the slowdown of industrial growth. After 2016, excess capacity has become the focus of Chinese policy. Financial policy, monetary policy, exchange rate and capital account policy have a significant positive effect on the substantial economic growth.

As for the negative impact of IAVG on EPU, it can be seen that substantial economic development has significantly affected the introduction of exchange rate and capital account policies, and the effect time is also longer, followed by monetary policy and trade policy. But in recent years, the impact of substantial economic growth on trade policy is no longer significant, in addition, the whole sample range of $\mathrm{EPU}_{f}$ by influenced by IAVG is relatively short, only reflected in a significant range. In terms of the effect of IAVG on various EPU, the former has a positive effect on the latter in the significant range before 2016. After 2016, IAVG has restrained the increase of economic policy uncertainties, especially monetary policy, exchange rate and capital account policy.

\section{Conclusion}

Under the background of the increasing instability of the economic policy environment, how to promote the steady growth of substantial economy has been put on the agenda. This paper analyzes the dynamic causal relationship between economic policy uncertainty and substantial economy growth by bootstrap rolling window causality test. The results show that: first, in the significant range of the whole sample, China's economic policy uncertainty has a significant inhibitory effect on the substantial economic growth. Second, the substantial economic growth will push up the degree of economic policy uncertainty before 2016, and restrain the increase of economic policy uncertainty after 2016. Third, specific to different types of economic policies: fiscal policy and monetary policy as China's main policy means, the increase in the policy uncertainty can affect the growth of the substantial economy in multiple intervals, but the action time is relatively short. Trade policy uncertainty significantly inhibited the growth of China's substantial economy during the financial crisis, and the effect time was relatively long. However, after the financial crisis, trade policy had no significant impact on the growth of China's substantial economy. Before 2020, exchange rate and capital account policy uncertainty has no obvious effect on China's substantial economic growth. However, the exchange rate and capital account policies have promoted China's substantial economic growth after 2020. On the other hand, in the whole sample interval, substantial economic growth has a significant impact on three kinds of economic policy uncertainties except fiscal policy, especially monetary policy, exchange rate and capital account policy uncertainties.

As the main means of government intervention in the economy, the introduction of economic policies plays a certain role in reducing economic fluctuations. However, the increase of uncertainty in economic policies is not conducive to the formation of stable expectations of market players, aggravating the risk of market transactions, increasing enterprise financing friction, and attacking the enthusiasm of market participants, which is not conducive to the efficient development of the substantial economy. Thus, first, the government should prudently implement economic policies, reduce the uncertainty at the government level from the root, try to reduce the negative effects of economic policies, and stabilize the expectations of all parties; second, it is necessary to build a policy information and data sharing platform to make the policy objectives, policy content and policy timeliness open and transparent, so as to give the market participants confidence and reduce the expected unstable factors; Finally, in the process of government intervening in the market, the government should try to reduce the direct help to enterprises, give full play to the role of

\section{Economic policy uncertainty}


MAEM

4,2

market competition, promote the innovation-driven development of enterprises through the effective competition between the same industry and different industries, and promote the development of China's substantial industries through the long-term mechanism of innovation.

\section{Note}

132 1. https://economicpolicyuncertaintyinchina.weebly.com/

\section{References}

Bachmann, R., Elstner, S. and Sims, E.R. (2013), "Uncertainty and economic activity: evidence from business survey data”, American Economic Journal: Macroeconomics, Vol. 5, pp. 217-249.

Baker, S.R., Bloom, N. and Davis, S.J. (2016), "Measuring economic policy uncertainty", Quarterly Journal of Economics, Vol. 131, pp. 1593-1636.

Basu, S. and Bundick, B. (2017), "Uncertainty shocks in a model of effective demand", Econometrica, Vol. 85, pp. 937-958.

Bloom, N. (2001), "The substantive options effect of uncertainty on investment and labor demand", IFS Working Paper, No.W00/15.

Bloom, N. (2009), "The impact of uncertainty shocks", Econometrica, Vol. 77, pp. 623-685.

Bomberger, W.A. (1996), "Disagreement as a measure of uncertainty", Journal of Money, Credit, and Banking, Vol. 28, pp. 381-392.

Caldara, D., Fuentes-Albero, C., Gilchrist, S. and Zakrajšek, E. (2016), "The macroeconomic impact of financial and uncertainty shocks", European Economic Review, Vol. 88, pp. 185-207.

Cecchetti, S.G. and Kharroubi, E. (2012), "Reassessing the impact of finance on growth", BIS WP, pp. 381-382.

Chen, G.J. and Wang, S.Q. (2016), "How does economic policy uncertainty influence corporate investment behavior?", Finance and Trade Economics, Vol. 5, pp. 5-21.

Cheng, S.W. (2003), "Probing into the details of fictitious economy", Nankai Journal (Philosophy, Literature and Social Science Edition), Vol. 2, pp. 23-28.

Claessens, S., Kose, M.A. and Terrones, M.E. (2009), "Study on the performance of one's own study", Economic Policy, Vol. 24, pp. 653-700.

Dore, R. (2008), "Financialization of the global economy", Industrial and Corporate Change, Vol. 17, pp. 1091-1112.

Doshi, H., Kumar, P. and Yerramilli, V. (2017), "Uncertainty, capital investment, and risk management”, Management Science, Vol. 64, pp. 594-612.

Easterly, W. and Joseph, E.S. (2000), Shaken and Stirred: Explaining Growth Volatility, Working Paper, The World Bank.

Efthyvoulou, G. and Vahter, P. (2015), "Financial constraints, innovation performance and sectoral disaggregation”, Manchester School, Vol. 84, pp. 125-158.

Gu, X.M., Chen, Y.M. and Pan, S.Y. (2018), "Economic policy uncertainty and innovation: evidence from listed companies in China”, Economic Research Journal, Vol. 53, pp. 109-123.

Gu, Q., Wang, W.W. and Li, M. (2020), "Economic policy uncertainty, institutional investors and R\&D investment_— based on the perspective of R\&D heterogeneity", Soft Science, Vol. 34, pp. 21-26.

Han, S., Enrico, P. and Sjoerd, V.B. (2017), "Substantive options and institutions", Journal of International Business Studies, Vol. 48, pp. 1-25.

Han, G.G. and Hu, W.M. (2016), "Macroeconomic uncertainty, entrepreneurial confidence and fixed assets investment-Based on province level dynamic panel data in China with SYS-GMM method", Finance and Economics, Vol. 213, pp. 79-89. 
Hao, W.Y., Wei, W. and Wen, J. (2016), "How does policy uncertainty influence firm Innovation? An effect mechanism based on the real option theory", Business Management Journal, Vol. 38, pp. 40-54.

Huang, Q.H. (2017), “On the development of China's real economy at the new stage”, China Industrial Economics, Vol. 9, pp. 5-24.

Huang, Y. and Luk, P. (2020), "Measuring economic policy uncertainty in China", China Economic Review, Vol. 59, p. 101367.

Ibrahim, M. and Alagidede, P. (2017), "Financial development, growth volatility and information asymmetry in sub - saharan africa: does law matter?", South African Journal of Economics, Vol. 85, pp. 570-588.

Jermann, U. and Quadrini, V. (2012), "Macroeconomic effects of financial shocks", American Economic Review, Vol. 102, pp. 238-271.

Jurado, K., Ludvigson, S.C. and Ng, S. (2010), "Measuring uncertainty”, Science Electronic Publishing, Vol. 2, pp. 2-7.

Li, J.Z. and Liu, Y. (2019), "Trade policy uncertainty and R\&D investment: evidence from Chinese enterprises", Industrial Economics Research, Vol. 6, pp. 1-13.

Li, P.F. and Sun, J.B. (2018), "Economic policy uncertainty, financial friction and decline of private investment growth", Journal of Zhengzhou University (Philosophy and Social Sciences Edition), Vol. 51, pp. 45-52+155.

Lind, J.T. and Mehlum, H. (2010), "With or without u? The appropriate test for a U-shaped relationship", Oxford Bulletin of Economics and Statistics, Vol. 72, pp. 109-118.

Liu, X.X. (2011), "The systematization of individual risk and financial crisis_—an explanation from fictitious economics", China Review of Political Economy, Vol. 2, pp. 64-80.

Mao, Q.L. (2020), "Does trade policy uncertainty affect Chinese manufacturing firms' imports?", Economic Research Journal, Vol. 55, pp. 148-164.

Martin, A. and Ventura, J. (2012), "Economic growth with bubbles", American Economic Review, Vol. 102, pp. 3033-3058.

Raghuram, G.R. and Luigi, Z. (1998), "Financial dependence and growth", The American Economic Review, Vol. 88, pp. 539-556.

Rao, P.G., Yue, H. and Jiang, G.H. (2017), "Economic policy uncertainty and firms' investment”, The Journal of World Economy, Vol. 40, pp. 27-51.

Ross and Levine (1997), "Financial development and economic growth: views and agenda", Journal of Economic Literature, Vol. 35, pp. 688-726.

Segal, G., Shaliastovich, I. and Yaron, A. (2015), "Good and bad uncertainty: Macroeconomic and financial market implications", Journal of Financial Economics, Vol. 117, pp. 369-397.

Scotti, C. (2016), "Surprise and uncertainty indexes: substantive-time aggregation of substantiveactivity macro-surprises", Journal of Monetary Economics, Vol. 82, pp. 1-19.

Shukur, G. and Mantalos, P. (2000), "A simple investigation of the granger-causality test in integrated cointegrated VAR systems", Journal of Applied Statistics, Vol. 27, pp. 1021-1031.

Shukur, G. and Mantalos, P. (2004), "Size and power of the reset test for systems of equations: a bootstrap approach", Journal of Modern Applied Statistical Methods, Vol. 3, p. 10.

Stein, L.C. and Stone, E. (2013), The Effect of Uncertainty on Investment, Hiring, and R\&D:Causal Evidence from Equity Options, Working Paper.

Stokey and Nancy, L. (2016), "Wait-and-see: investment options under policy uncertainty", Review of Economic Dynamics, Vol. 21, pp. 246-265.

Wang, R. and Li, L.F. (2019), "Time-varying analysis on the monetary policy regulation and house price fluctuations in China_-new evidence based on the bootstrap rolling window causality test”, Shanghai Journal of Economics, Vol. 8, pp. 86-97.

Economic policy uncertainty 
MAEM

4,2

134

Wang, D.M. and Lu, C.Y. (2019), "Economic policy uncertainty, financial development, and international capital flows", Economic Perspectives, Vol. 12, pp. 75-93.

Wang, Q.Z.and Wang,Y.D.(2018), "International transmission of volatility among crude oil prices, economic uncertainty and the stock market", Chinese Journal of Management Science, Vol. 26, pp. 50-61.

Wang, B., Li, L. and Hao, D.P. (2019), "Monetary policy uncertainty, default risks and macroeconomic fluctuations", Economic Research Journal, Vol. 54, pp. 119-134.

Wu, S.S. and Lin, Z.M. (2006), "Positioning the 'new' economy from the perspective of generalized virtual economy”, Reform of Economic System, Vol. 2, pp. 12-16.

Yang, Z.H., Chen, L.X. and Chen, Y.K. (2020), "Cross-market contagion of economic policy uncertainty and systemic financial risk: a nonlinear network connectedness analysis", Economic Research Journal, Vol. 55, pp. 65-81.

Yu, S.Y. and Song, X.F. (2020), "Research on the difference of impact effects of uncertain shocks on macroeconomic variables: based on the perspective of financial friction zone system", Journal of Sun Yat-Sen University (Social Science Edition), Vol. 60, pp. 170-181.

Zhang, Q.X. and Feng, L. (2018), "Macroeconomic policy uncertainty and corporate technological innovation-evidence from China's listed companies", Modern Economic Science, Vol. 40, pp. $48-57+126$.

Zhang, L., Lian, Y.H. and Xin, B.H. (2015), "Macroeconomic uncertainty, bank heterogeneity, and credit supply”, Contemporary Economic Science, Vol. 37, pp. 60-71+126.

Zhang, F., Liu, X.Y., Wu, L.D. and Yin, X.L. (2019), "Product innovation or service transition: economic policy uncertainty and manufacturing innovation choice”, China Industrial Economics, Vol. 7, pp. 101-118.

Zhou, X.C. (2011), "The financial sector should focus on supporting the substantive economy", Financial News, December 21, 2011.

\section{Corresponding author}

Shan Huang can be contacted at: huangshan201411@163.com

For instructions on how to order reprints of this article, please visit our website:

www.emeraldgrouppublishing.com/licensing/reprints.htm

Or contact us for further details: permissions@emeraldinsight.com 